\title{
Preparation and characterization of powdered and granular activated carbon from Palmae biomass for mercury removal
}

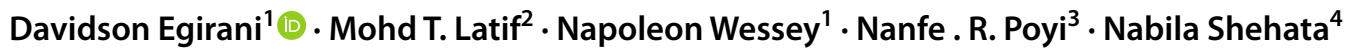

Received: 1 November 2019 / Accepted: 14 December 2020 / Published online: 3 January 2021

(c) The Author(s) 2021

\begin{abstract}
Two forms of activated carbon (i.e., granular and powdered forms) used to test mercury removal in solution. These activated carbons were obtained from the shells of a palmae biomass and used in mercury ion removal in aquatic systems. The African palmae shell taken out from a broadly and simply full-fledged palm tree. This biomass serves as a precursor in the formulation of activated carbons not documented. The powdered and granular fractions of activated carbons described for chemical composition, isoelectric point, and surface area. The mechanism of reactions and the kinetics involved were studied using the results of protonation and rate limitations. The parameters used in the batch mode study included $\mathrm{pH}$, contact time, initial concentration of the adsorbate and the dose of the activated carbons. A comparison of performances, contact time demonstrated the highest adsorption efficiency of $93 \%$ for the powdered activated carbon and $92 \%$ for the granular activated carbon. The dosage recorded the lowest adsorption efficiency of $84 \%$ using granular activated carbon. Comparatively, this study brought to the fore that activated carbon derived from the Plamae biomass remains a novel bio-sorbent
\end{abstract}

Keywords Powdered activated carbon $\cdot$ Granular activated carbon $\cdot$ Mercury removal $\cdot$ African palmae shell

\section{Introduction}

Mercury $(\mathrm{Hg})$, Lead $(\mathrm{Pb})$, and Cadmium $(\mathrm{Cd})$ considered as toxic metals. Their presence in the aquatic environment above recommended limits is critical to human health and

Davidson Egirani

eenonidavidson@yahoo.com

Napoleon Wessey

napwessey@yahoo.com

Mohd T. Latif

talib@ukm.edu.my

Nanfe . R. Poyi

nanfe06@yahoo.com

Nabila Shehata

nabila.shehata@yahoo.com

1 Faculty of Science, Niger Delta University, Wilberforce Island, Nigeria

2 School of Environmental and Natural Resource Sciences, Universiti Kebangsaan, Bangi, Malaysia

3 Nigerian Defence Academy, Kaduna, Nigeria

4 Faculty of the Postgraduates Studies for Advanced Sciences, Beni-Suef University, Beni-Suef, Egypt the ecosystem. The presence of mercury in the aquatic environment and the ecosystem remains an area of research interest because of the toxic nature of mercury to humans. The characteristic of non-biodegradability supports the persistency of mercury ions in the system (Šapanin et al. 2019). Mercury ions released into the environment from ores, industries, and agricultural waste. These ions are transported along the eco-chain into humans resulting in food poisoning, liver, kidney malfunctioning, and carcinogenicity (Mousavi et al. 2011; Alam et al. 2019; Avigliano et al. 2019).

There is a need to reduce the presence of $\mathrm{Hg}$ (II) ions from solution. The techniques in current use include membrane filtration, oxidation, sedimentation, distillation, ion exchanger, and adsorption (Abdel-Ghani et al. 2014; Abdolali et al. 2014). All these process and techniques have several setbacks range from high cost, the high volume of waste, and the inability to achieve the limits required by the international community (Páez-Hernández et al. 2005). Mercury ion removal using adsorption is considered an accepted technique since it is simple, less expensive, and environmental friendly (Chen et al. 2019).

The use of activated carbon as an adsorbent in mercury ion removal exists. The desirability to use activated carbon stems from the fact that activated carbon contains well 
oriented structural carbon atoms. However, the extra cost of growing bio-materials is problematic, thus readily grown bio-materials such as the African palmae is an added advantage (Thambiliyagodage et al. 2018; Sadegh et al. 2017). The development of activated carbon takes different forms inclusive pyrolysis at high temperature (physical activation) and the use of chemical reagents at low temperature (Jankovi et al. 2019). The use of chemical reagents is preferable since low temperature and shorter time is involved. Besides, the extra surface area added to improve on the reactivity of the activated carbon (Di Stasi et al. 2019). Among the activating reagents, potassium hydroxide is considered the best since it generates high surface area and high porosity of the activated carbon (Yacob et al. 2010; Yang et al. 2019; Wan et al. 2019; Vazquez et al. 2002). The interaction of activated carbon and some mercury ions controlled by the adsorption characteristics of net proton charge and the surface area (Ghaith et al. 2019; Skinner et al. 2007). A Weber-Morris model is an excellent tool in the validation of intra-particle diffusion (Ghannad and Lotfollahi, 2019). The Freundlich isotherm and the extended forms are useful in validating the reaction kinetics of the reaction processes \{Yang et al. 2019; Fuadi et al. 2014; Lotfy et al. 2012).

There are several spilt cases of mercury in the environment. Some of these cases could be due to the careless release of mercury from the laboratories, manufacture, and mining operations. In this study, the treatment of mercury in solution with a well prepared and characterized, activated carbon derived from Palmae biomass is done.

\section{Materials and experimental methods}

\section{Material preparation}

Local communities in Nigeria provide the sampled Palmae shells used as precursor used for the formulation of the activated carbon. The samples were cleaned and air-dried using tap water at a moisture content of $10 \%$. The samples were carbonized and fractionated into powdered and granular forms of $0.6 \mathrm{~mm}$ and $1.5 \mathrm{~mm}$, respectively (Ani et al. 2020). The purpose for the fraction is to understand the role of particle fractions in the efficiency of the activated carbons.

\section{Formulation of activated carbon}

The carbonization process involved heating of the shells to $4000{ }^{\circ} \mathrm{C}$ until the shells turned into a large volume of charcoal. The charcoal was then chemically activated using $75 \%$ potassium hydroxide at a moderate temperature of $400{ }^{\circ} \mathrm{C}$ for $5 \mathrm{~h}$. The activation was carried out in the ratio of 3:1 (carbon: activator) to form a paste. A muffle furnace in an atmosphere of neutral gas $\left(\mathrm{N}_{2}\right)$ used to heat the paste until dried. The content rinsed with distilled water at ambient temperature. Subsequently, the rinsed and dried content was dried at $105{ }^{\circ} \mathrm{C}$ for $24 \mathrm{~h}$ to ensure wholistic drying. Again, the content subjected to further pulverization to achieve the PAC- $0.6 \mathrm{~mm}$ and GAC- $1.5 \mathrm{~mm}$ fractions. The content ready for adsorption experiments (Bani et al. 2018; Hui and Zaini, 2015). A set of reactions occurring during the activation process is provided:

$\mathrm{C}+2 \mathrm{KOH} \rightarrow 2 \mathrm{~K}+\mathrm{H}_{2}+\mathrm{CO}_{2}$

$\mathrm{C}+2 \mathrm{KOH} \rightarrow 2 \mathrm{~K}+\mathrm{H}_{2} \mathrm{O}+\mathrm{CO}$

$\mathrm{CO}_{2}+2 \mathrm{KOH} \rightarrow \mathrm{K}_{2} \mathrm{CO}_{3}+\mathrm{H}_{2} \mathrm{O}$

\section{Characterization of biomass and activated carbon}

\section{Proximate analysis}

A carbonized shell contains physical and chemical components distributed over the carbon structure. These include the water present in the sample (i.e., moisture content), gases and vapors (i.e., volatile matter), and the fixed carbon contained in the sampled. The moisture content was determined by heating the sample at $105{ }^{\circ} \mathrm{C}$ for $2 \mathrm{~h}$ in a petri dish and recording the difference in weight before and after heating of the sample. The volatile matter was determined by heating the sample in a crucible at $925^{\circ} \mathrm{C}$ for $7 \mathrm{~min}$ and recording the difference in weight before and after heating of the sample. The ash content was evaluated by heating the sample at $725{ }^{\circ} \mathrm{C}$ for $1 \mathrm{~h}$ and recording the difference in weight before and after heating of the sample. The fixed carbon content was evaluated by recording the difference between $\%$ of moisture content, volatile matter content, and ash content from 100 (Budianto et al. 2019).

\section{Ultimate analysis (CHNS)}

The determination of carbon, hydrogen, nitrogen, and sulfur in biomass CHNS analysis. This Dumas technique centered on the full oxidation of the precursor expressed, in the CHNS components. The \% of oxygen-derived by recording the difference between the CHNS and 100 (Fleck 1965). The CHNS Analyzer LabX, Ontario, Canada was used for the ultimate analysis. The reaction of the precursor and excess oxygen releases carbon dioxide, water, nitrogen dioxide, and sulfur dioxide, respectively. A chromatographic column was used for the separation of these components, detected by a thermal conductivity detector (TCD.). The signals from the TCD were related to the concentration of the components of the biomass (Zheng et al. 2019). 


\section{Determination of the point of zero charges of activated carbon}

The point of zero charges ( $\mathrm{pHpzc}$ ) indicates a $\mathrm{pH}$ value of zero. This parameter indicates the interface between the positive and negative charges at the active sites. A potentiometric titration involving $0.001 \mathrm{M}, 0.01 \mathrm{M}$, and $0.1 \mathrm{M}$ of $\mathrm{NaCl}$ electrolyte, and $1 \mathrm{~g}$ activated carbon reacted for $24 \mathrm{~h}$ was used to evaluate this parameter. The titration curves generated by a plot of net proton charges versus the suspension $\mathrm{pH}$ were used to determine the $\mathrm{pHpzc}$.

\section{Morphological study of the activated carbons}

The scanning electron microscopy (SEM-EDX method) (EMLS-Canada) was used to perform the image analysis of the activated carbons. A high vacuum mode (HV) was used to observe the analyzed samples at the accelerated voltage of $20 \mathrm{kV}$ or $10 \mathrm{kV}$ using an SE secondary electron detector.

\section{Determination of surface area of activated carbon}

The physical adsorption of nitrogen gas on the surface of the $\mathrm{AC}$ was used to evaluate the equivalent nitrogen gas adsorbed to a single layer on the activated carbon surface. monomolecular layer on the surface. A micromeritics (ASAP 2020) surface area analyzer LabX, Ontario, Canada was used to degas the sample at $300{ }^{\circ} \mathrm{C}$ in liquid nitrogen flow condition (Stoeckli and Centeno, 2005).

\section{Regeneration of the activated carbon}

Thermal regeneration of the spent activated carbon was carried out by treating it with $1 \mathrm{M}$ nitric acid, thus resulting to $60 \%$ regain. The extracted activated carbon was heated to $500{ }^{\circ} \mathrm{C}$ for $24 \mathrm{~h}$ (Shahadat, and Isamil 2018).

\section{Adsorption experiments}

All chemicals and materials used for analyses were of analytical grade purity obtained from BDH (England), Loba Chemie (India). $1 \mathrm{~g}$ of mercury chloride was dissolved in distilled and made up to a liter. This content is the stock solution, and several standards were prepared from the stock solution. The equilibrated experiments on batch mode adsorption were administered using $20 \mathrm{~g} / 50 \mathrm{~mL}$ of mercury solution. The suspension since agitation for 30 min except for contact time experiments and filtered with $0.45 \mu \mathrm{m}$ membrane was measured for $\mathrm{Hg}$ (II) ions remaining in a solution using ICP-OES analyzer
(CAP6300, Thermo, USA). The adsorption capacity of the AC Qe (mg/g) was determined (Eq. 1):

The adsorption capacity of the AC Qe (mg/g) was calculated using the following Eq. (1):

$Q_{e}=\left[C_{0}-C_{e}\right]^{V / M}$

Herein, $\mathrm{C} 0$ and $\mathrm{Ce}$ define the concentration at the start of reaction and concentration at the steady- state of the $\mathrm{Hg}$ (II) ions $(\mathrm{mg} / \mathrm{L})$ and contaminated water interaction, respectively, $\mathrm{V}$ is the volume of the solution (L), and $\mathrm{m}$ is the mass of AC used $(\mathrm{g})$. The exchange of protons has a constant defined by an isotherm deduced from the plot of the change in $\mathrm{pH}$ versus $\lg \mathrm{Kd}$ as provided (Eqs. (5) and (6):

$\alpha \mathrm{SOH} \leftrightarrow \mathrm{SO}^{-}+\alpha \mathrm{H}^{+}$

$1 g \mathrm{Kd} \leftrightarrow 1 g\left(K_{p}\{\mathrm{SOH}\} \alpha\right)+\alpha p H$

Herein, $\mathrm{SOH}$ represents an $\mathrm{AC}$ surface-reactive site, $\mathrm{SO}-$ is the surface-bound $\mathrm{Hg}(\mathrm{II}), \operatorname{lgKp}$ is the apparent equilibriumbinding constant, and $\alpha$ is the coefficient of protonation, which represents the number of protons displaced when one mole of $\mathrm{Hg}$ (II) binds to the AC surface.

Also, the mass transfer rate and intraparticle diffusion were derived from Eqs. (8)- (9):

$Q_{t}=\left[C_{0}-C_{t}\right]^{V / M}$

Herein, $\mathrm{C}_{0}$ is the initial $\mathrm{Hg}(\mathrm{II})$ concentration $\left(\mathrm{mg} \cdot \mathrm{L}^{-1}\right)$ at time $t=0 ; \mathrm{C}_{\mathrm{t}}$ is the concentration $\left(\mathrm{mg} \cdot \mathrm{L}^{-1}\right)$ at time $t ; \mathrm{V}$ is the total suspension volume, and $\mathrm{m}$ is the mass of the $\mathrm{AC}(\mathrm{g})(\mathrm{Oje}-$ maye et al. 2017).

An intraparticle diffusion model by Weber-Morris also, was used to describe the reaction mechanism as provided (Eq. 8) (Dong, 2012):

A reaction kinetic involving $\mathrm{AC}$ charged with $\mathrm{Hg}$ (II) ions was deduced from the mass transfer constant $\mathrm{K}_{\mathrm{f}}$. Here, $\mathrm{C}_{\mathrm{t}} / \mathrm{C}_{0}$ versus time provided the slopes of the curves derived from Eq. (8) \{Joseph et al. 2019\}.:

$\left[\frac{d\left(C_{t} / C_{0}\right)}{d t}\right]_{t=0} \cong-K_{f} S_{s}$

Herein, $C_{0}$ and $C_{t}$ represent the $\mathrm{Hg}$ (II) initial concentration at time $t, S_{s}$ is the exposed surface area of an $\mathrm{AC}$, and $K_{\mathrm{f}}$ is the coefficient of mass transfer. These models as derived from the Freundlich isotherm have been reviewed previously and adopted to describe the adsorption of $\mathrm{Hg}$ (II) ions(Mohan and Chander 2001).

$Q_{t}=K_{t^{0.5}}+C$ 
Herein, $K_{i}$ is the intraparticle diffusion constant $\left(\mathrm{mg} \cdot \mathrm{g}^{-1} \cdot \mathrm{min}^{-1}\right.$ ), and the intercept (C) represents the effect of the layer boundary. The value of $K_{i}$ is derived from the slope $\left(K_{i}\right)$ of the plots of $Q_{t}$ vs. $t^{0.5}$. A linear plot of $Q_{t}$ versus $t^{0.5}$ indicates that intraparticle diffusion was involved in the process of adsorption [Li et al. 2016]. For validation of an intraparticle diffusion, a $10 \mathrm{mg} \cdot \mathrm{L}^{-1} \mathrm{Hg}$ (II) solution was charged with $20 \mathrm{~g}$ of $\mathrm{AC}$ made up to $50 \mathrm{~mL}$ at $4 \leq \mathrm{pH} \leq 10$. This mixture was treated for $30,60,90,120,150,180$, and $210 \mathrm{~min}$. $\mathrm{A} \mathrm{Hg}(\mathrm{II})$ ions remaining in solution were determined using the ICP-OES. In all experiments, the adsorption efficiency of AC was calculated from Eq. (10):

Adsorption efficiency $(\%)=\frac{C_{0}-C_{e}}{C_{0}} \times 100$

Herein, $C_{0}$ and $C_{\mathrm{e}}\left(\mathrm{mg} \cdot \mathrm{L}^{-1}\right)$ are the concentrations at the start of reaction and concentration at the steady-state $\mathrm{Hg}$ (II) concentrations in solution, respectively (Zbair et al. 2019; Awual, 2017).

Besides the Freundlich isotherm and its derivatives used in this study, the Langmuir adsorption isotherm is used to describe the adsorption kinetics. $A$ linear regression $(y=A+B \cdot x)$ and Langmuir equation are represented

$C_{e} / q_{e}=\frac{1}{q_{m} * b}+\frac{C_{e}}{q_{m}}$

Herein, $C_{\mathrm{e}}$ is the equilibrium concentration of cadmium $(\mathrm{mg} / \mathrm{L})$ in solution, $\mathrm{q}_{\mathrm{e}}$ is the adsorption capacity of the activated carbon at equilibrium $(\mathrm{mg} / \mathrm{g}), \mathrm{q}_{\mathrm{m}}$ is the maximum adsorption capacity of the activated carbon $(\mathrm{mg} / \mathrm{g})$ and $\mathrm{b}(\mathrm{L} / \mathrm{mg})$ is a constant linked to the energy of adsorption. A plot of $C_{e} / q_{e}$ versus $C_{e}$ gives a slope of $\frac{1}{q_{m}}$ and an intercept $\frac{1}{q_{m} * b}$.

$\mathrm{y}=\mathrm{A}+\mathrm{B}^{*} \mathrm{x} ; \mathrm{y}=C_{e} / q_{e} ; \mathrm{x}=C_{e} ; \mathrm{A}=\frac{1}{q_{m} * b} ; \mathrm{B}=\frac{1}{q_{m}}(12)$.

If the adsorption process falls in line with the Langmuir model, then the plot provides a straight line, and the values of $\mathrm{q}_{\mathrm{m}}$ and $\mathrm{b}(\mathrm{L} / \mathrm{mg})$ are evaluated from the plot.

\section{Effect of $\mathrm{pH}$ on the removal of $\mathrm{Hg}$ (II) removal}

At a constant contact time (30 min), dosage ( $20 \mathrm{~g})$, and some mercury concentration $(20 \mathrm{mg} / \mathrm{L})$ the effect of $\mathrm{pH}$ was also studied. $20 \mathrm{~g}$ of the activated carbon was introduced into a $50 \mathrm{~mL}$ plastic vial. The content was made up to $50 \mathrm{~mL}$ by adding the mercury-contaminated carnal water and $0.1 \mathrm{M}$ of $\mathrm{NaOH}$ was used to regulate the $\mathrm{pH}$ to $\mathrm{pH} 4,5,6,7,8,9$, and 10 . The solution was shaken and filtered with $0.45 \mu \mathrm{m}$ filter paper. The Remaining mercury in solution was determined using inductively coupled plasma optical emission spectrometer (ICP-OES analyzer CAP6300, Thermo, USA).

\section{Effect of contact time on the removal of $\mathrm{Hg}$ (II) Removal}

At a constant $\mathrm{pH}$ of $6.05,20 \mathrm{~g}$ dosage and some mercury concentration of $20 \mathrm{mg} / \mathrm{L}$, the effect of contact time on mercury removal was also studied at a range of 30, 60, 90, 120, 150,180 , and $210 \mathrm{~min} .20 \mathrm{~g}$ of the activated carbon was introduced into a $50 \mathrm{~mL}$ plastic vial. The content was sealed and placed in a mechanical shaker and agitated at 20 rotation per minute (rpm), for each of the different contact times (30, $60,90,120,150,180$, and $210 \mathrm{~min}$ ). The content of each was filtered and analyzed with ICP-OES analyzer (CAP6300, Thermo, USA) to determine the amount of mercury remaining in the solutions.

\section{Effects of $\mathrm{Hg}$ concentration on its removal by activated carbon}

At a constant $\mathrm{pH}$ of 6.05 , a contact time of $30 \mathrm{~min}$ and $20 \mathrm{~g}$ dosage of activated carbon, the effect of $\mathrm{Hg}$ concentration on its removal by activated carbon was studied. $20 \mathrm{~g}$ of the activated carbon was introduced into a $50 \mathrm{~mL}$ plastic vial. The content was made up to $50 \mathrm{~mL}$ by adding variable concentrations of mercury solutions at $40 \mathrm{mg} / \mathrm{L}, 20 \mathrm{mg} / \mathrm{L}$, $15 \mathrm{mg} / \mathrm{L}$, and $10 \mathrm{mg} / \mathrm{L}$. The content was sealed and placed in a mechanical shaker and agitated at 20 rotations per minute (rpm). The content was filtered and analyzed with ICP-OES analyzer (CAP6300, Thermo, USA) to determine the amount of mercury remaining in the solutions.

\section{The effect of dosage of activated carbon on the removal of $\mathrm{Hg}(\mathrm{II})$ ions}

At a constant $\mathrm{pH}$ of 6.05 , a contact time of 30 min a mercury concentration of $20 \mathrm{mg} / \mathrm{L}$, the effect of dosage of activated carbon on mercury removal was studied. 10, 20,30, and $40 \mathrm{~g}$ of the activated carbon were introduced into a $50 \mathrm{~mL}$ sample vial. The content was made up to $50 \mathrm{~mL}$ by adding $20 \mathrm{mg} / \mathrm{L}$ of mercury solution. The content was sealed and agitated in a mechanical shaker at a speed of 20 rotations per minute (rpm). The content was then filtered and analyzed with ICPOES analyzer (CAP6300, Thermo, USA) to determine the amount of mercury remaining in the solutions.

\section{Results}

\section{Characterization}

This study has made available the component distribution of moisture content, volatile matter, and the fixed carbon contained in the biomass. Besides, the CHNS components have been provided (Tables 1 and 2). Thermal treatment of biomass decreased the content of the biomass to $39.2 \%$. The 
Table 1 Proximate and ultimate analysis of powdered palmae shells and granular palmae shells

Table 2 Proximate and ultimate analysis of powdered activated carbon and granular activated carbon
Ultimate or CHNS Analysis of PPS and GPS

\begin{tabular}{lrr}
\hline Composition & \multicolumn{1}{l}{ PPS } & \multicolumn{1}{l}{ GPS } \\
& Wt. \% & \multicolumn{1}{l}{ Wt. \% } \\
Carbon (\%) & 47.23 & 47.54 \\
Hydrogen (\%) & 6.88 & 6.47 \\
Nitrogen (\%) & 0.77 & 1.03 \\
Sulfur (\%) & .25 & 0.62 \\
Oxygen (\%) & 44.86 & 44.33 \\
\hline
\end{tabular}

Ultimate or CHNS Analysis of PAC and GAC

\begin{tabular}{lrr}
\hline Composition & \multicolumn{1}{c}{ PAC } & \multicolumn{1}{c}{ GAC } \\
& Wt. \% & Wt. \% \\
Carbon (\%) & 75.00 & 75.26 \\
Hydrogen (\%) & 1.88 & 2.08 \\
Nitrogen (\%) & .54 & .64 \\
Sulfur (\%) & 0.10 & 0.21 \\
Oxygen (\%) & 22.48 & 21.81 \\
\hline
\end{tabular}

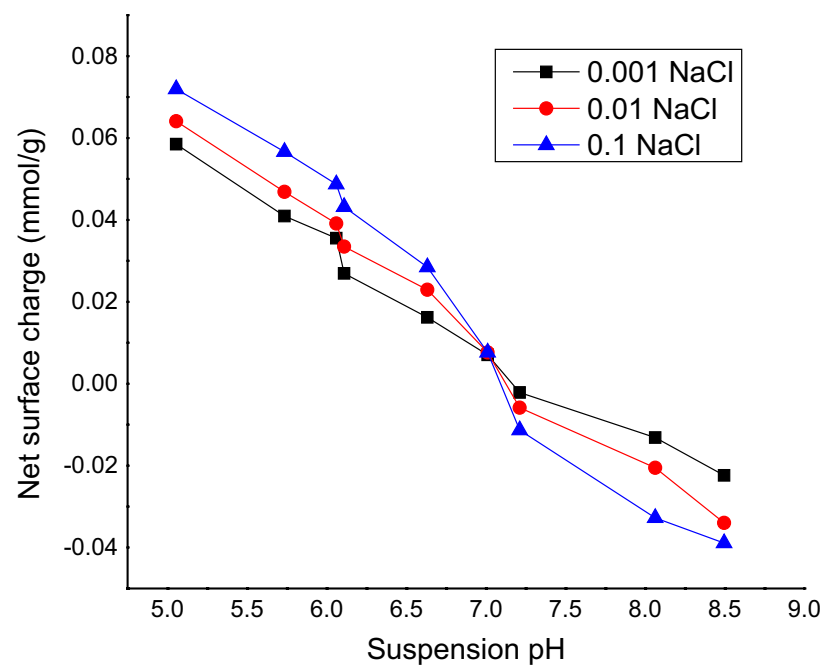

Fig. 1 Plot of net surface charge versus suspension $\mathrm{pH}$ of activated carbon for determination of the point of zero charges

sudden increase in the amount of fixed carbon and decrease in the amount of hydrogen may be linked to volatile matter removed during carbonization and subsequent activation of the biochar. Palmae shell does not carry nitrogen as a component, rather it was introduced during the carbonization process. Also, a significant amount of oxygen is lost during the activation process.

The pHpzc of activated carbon is 7.01 (Figs. 1 and 2 ). This value indicates that above the pHpzc, the active surface of the activated carbon is negatively charged. The actual mineral surface subject to reaction is controlled by the specific surface area. This is determined using the Brunauer-Emmett-Teller (BET) method. The powdered and granular forms of the activated carbon generated a surface area $3520 \mathrm{~m}^{2} / \mathrm{g}$ and $2950 \mathrm{~m}^{2} / \mathrm{g}$, respectively. Equations (1) and (2) and a graphical plot (Fig. 3) were used to evaluate the proton coefficient $(\alpha)$, of the reactions. The graph provided a linear fit trend (Table 3). The value of $\alpha$ for powdered (PAC) and the granular (GAC) forms of activated carbon as provided by the slopes are 1.12 and 0.38 , respectively.

Thus, $\mathrm{lg} \mathrm{Kd}$ versus $\mathrm{pH}$ plot provided a peak distribution coefficient $(\mathrm{Kd})$ of $23.68 \mathrm{~L} / \mathrm{g}$ and $2.15 \mathrm{~L} / \mathrm{g}$ for powdered and granular forms of activated carbon, respectively. The mass transfer of $\mathrm{Hg}$ (II) ions from the surface to the reactive boundary ( Eq. 4) is generated from a plot of $\mathrm{Ct} / \mathrm{C} 0$ versus contact time (Fig. 4 and Table 3). The rate of particle diffusion in the reaction processes (Eqs. 5-6) is used to plot and provide slope values for the constant (Fig. 4, and Table 4).

The thermal regeneration of the spent activated carbon revealed a regain of $60 \%$ adsorption capacity. Thermal heating of the extracted activated carbon provided a $90 \%$ removal efficiency (Fig. 5).

\section{Adsorption studies}

The results obtained from the adsorption studies are shown Eq. (Figs. 6, 7, 8, 9, 10 and 11 and Tables 3, 4, 5, 6 and 7).

The Langmuir isotherm parameters are provided (Tables 2 and 4). The Langmuir constants for PAC are higher than that of the GAC, and the maximum adsorption is equally slightly higher for the PAC compared to the GAC.

\section{Effect of contact time on a $\mathrm{Hg}$ (II) removal}

The efficiency removal of mercury was plotted against contact time using Eq. 7 and found in Fig. 5. Two critical components of the plot revealed a steady increase in adsorption supported by an equilibrium outlook over time. The adsorption response is $78 \%$ and $74.5 \%$ at the 18 th mins for both PAC and GAC activated carbons, respectively.

\section{Effect of initial $\mathrm{Hg}(\mathrm{II})$ concentration on its removal}

The efficiency removal of mercury was plotted against $\mathrm{Hg}$ (II) concentration using Eq. 7 and found in Fig. 6. Two critical components of the plot reveal a decrease in $\mathrm{Hg}$ (II) removal as the concentration increases and subsequently achieved an equilibrium state over time. The maximum removal efficiencies are $87.5 \%$ and $81.25 \%$ for both the powdered and granular forms of activated carbons. 
Fig. 2 SEM micrographs of activated carbons a without treatment and $\mathbf{b}$ treated with mercury ions,
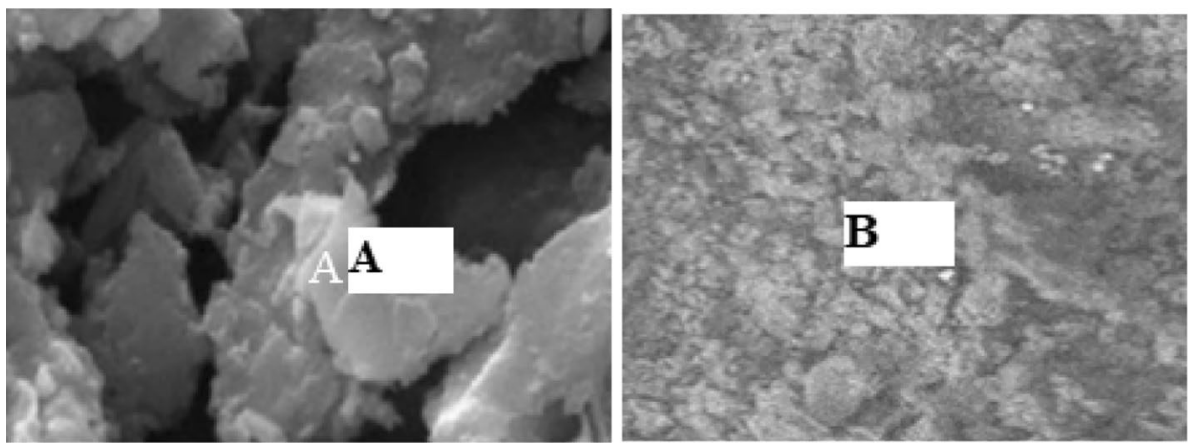

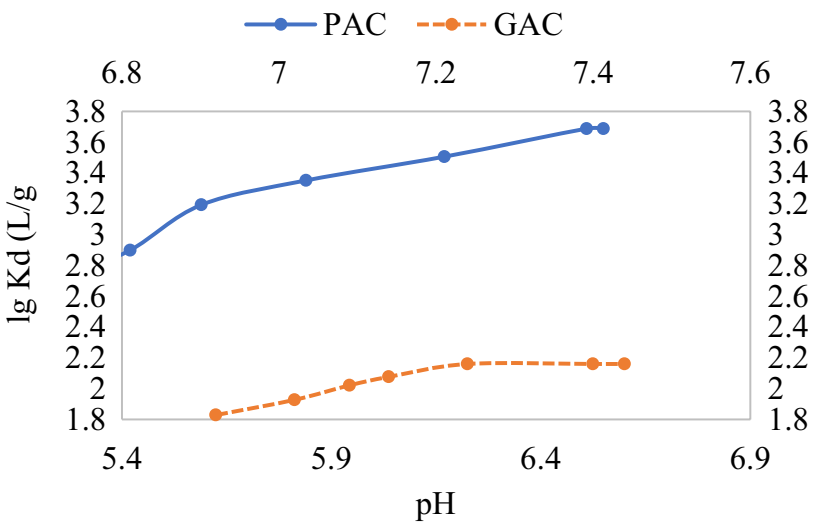

Fig. 3 Plot of $\mathrm{lg} \mathrm{Kd}$ versus final $\mathrm{pH}$ for proton coefficient for PAC and GAC

Table 3 Linear fit parameters derived from Fig. 2

\begin{tabular}{llll}
\hline Equation & $y=a+b^{*} x$ & PAC & \\
\hline & & Value & Standard error \\
$\lg \mathrm{Kd}(\mathrm{L} / \mathrm{g})$ & Intercept & 3.52 & $1.42 \times 10^{-5}$ \\
& Slope & 1.12 & $2.35 \times 10^{-6}$ \\
Equation & $y=a+b^{*} \mathrm{x}$ & $\mathrm{GAC}$ & \\
$\operatorname{lg~Kd}(\mathrm{L} / \mathrm{g})$ & Intercept & 0.29 & $4.91 \times 10^{-6}$ \\
& Slope & 0.38 & $8.11 \times 10^{-7}$ \\
\hline
\end{tabular}

\section{Effect of $\mathrm{pH}$ on $\mathrm{Hg}(\mathrm{II})$ removal}

In the range of $\mathrm{pH}$ studied, uptake of both charged and uncharged $\mathrm{Hg}$ (II) species exist with the latter dominating in solution. The uptake of $\mathrm{Hg}$ (II) ions appeared to increase increased $\mathrm{pH}$ as the hydronium increased. Within the alkaline range, the uptake of $\mathrm{Hg}$ (II) ions decreased and achieved a steady-state, The $\mathrm{pH}$ is critical to the adsorption of $\mathrm{Hg}$ (II) ions in solution (Reddy et al. 2014). At $\mathrm{pH}=7.01$, both the positives and negatives at the reactive surface are balanced, and adsorption is by coulombic forces. However, above the isoelectric point an equilibrium state of the reaction is achieved (Fig. 7). The maximum removal efficiencies are

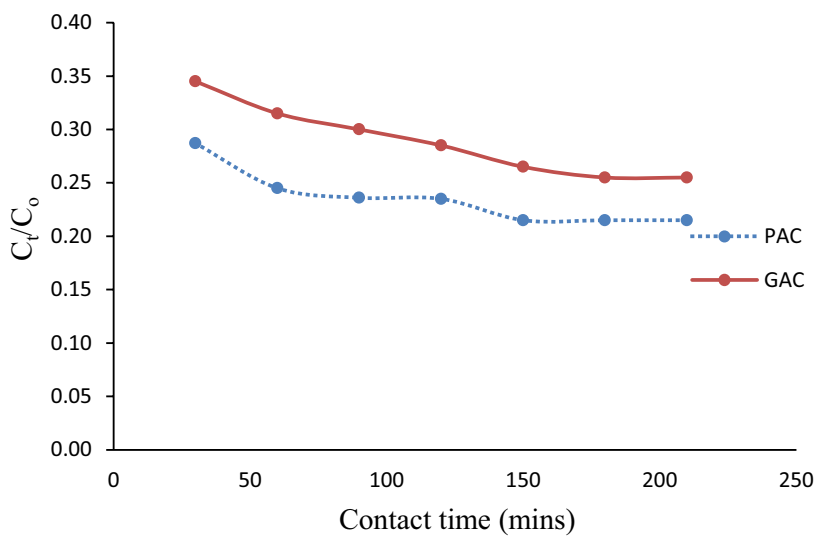

Fig. $4 \mathrm{C}_{\mathrm{t}} / \mathrm{C}_{\mathrm{o}}$ for $\mathrm{Hg}(\mathrm{II})$ versus contact tim

$88 \%$ PAC and $86.1 \%$ for both the powdered and granular forms of activated carbons.

\section{Effect of dosage of activated carbon on $\mathrm{Hg}$ (II) removal}

The efficiency removal of mercury was plotted against the dosage of the activated carbons using Eq. 7 and found in Fig. 8. Two critical components of the plot revealed a steady increase in adsorption supported by an equilibrium state over time. Herein, the maximum removal efficiencies are $71.5 \%$ and $64.5 \%$ for both the powdered and granular forms of activated carbons.

\section{Discussion}

\section{Adsorption and reaction mechanism}

The reaction mechanisms are characterized by the proton coefficient, diffusion of intraparticle and the transfer of $\mathrm{Hg}$ (II) ions from the boundary layer to the reactive sites (Ghannad and Lotfollahi, 2019). Here, when $\mathrm{Hg}$ (II) ions were charged with the activated carbons, the proton coefficients are less than one. There is a suggestion that the removal of $\mathrm{Hg}(\mathrm{II})$ ions is not solely a process initiated by 
Table 4 Analysis of mass transfer constant derived from Fig. 3

\begin{tabular}{llllll}
\hline $\begin{array}{l}\text { Activated Car- } \\
\text { bon Type }\end{array}$ & Slope 1 $\left(\mathrm{h}^{-1}\right)$ & Slope II $\left(\mathrm{h}^{-1}\right)$ & $\begin{array}{l}\text { Exposed surface } \\
\text { area }\left(\mathrm{cm}^{2}\right)\end{array}$ & $\mathrm{K}_{\mathrm{fI}}\left(\mathrm{cm}^{2} \mathrm{~h}^{-1)}\right.$ & $\mathrm{K}_{\mathrm{fII}}\left(\mathrm{cm}^{2} \mathrm{~h}^{-1)}\right.$ \\
\hline PAC & 0.147 & 0.0129 & 292,000 & $5.041 \times 10^{-7}$ & $4.42 \times 10^{-8}$ \\
GAC & 0.0717 & 0.0156 & 285,000 & $2.518 \times 10^{-7}$ & $5.48 \times 10^{-8}$ \\
\hline
\end{tabular}

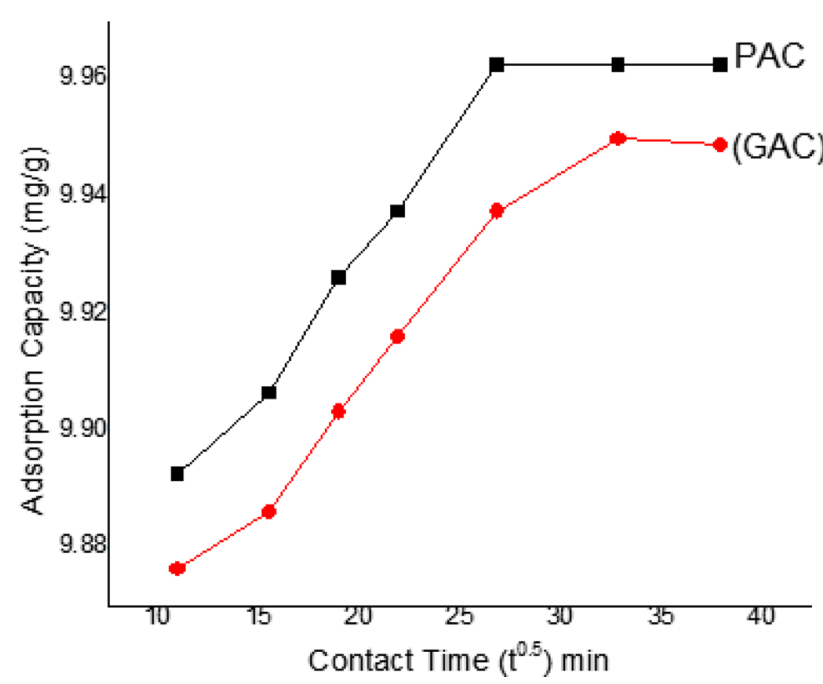

Fig. 5 A plot of adsorption capacity of PAC and GAC versus square root of contact time ( $\mathrm{min}$ ) for intra-particle diffusion

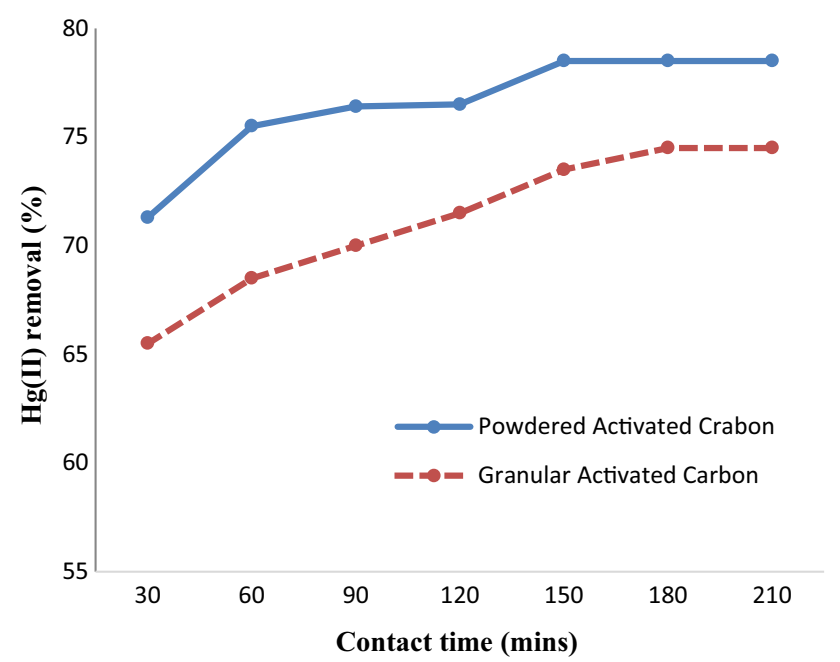

Fig. $6 \mathrm{Hg}$ removal (\%) versus Contact Time (mins) for powdered activated carbon (PAC) and granular activated carbon (GAC) $(20 \mathrm{~g}$ adsorbent, $\mathrm{pH}=6.05,40.41 \mathrm{mg} / \mathrm{L} \mathrm{Hg}$ (II) ions

the formation and utilization of protons. Instead, the diffusion of intraparticle with slopes $3.22 \times 10^{-3}$ and $3.22 \times 10-3$ (mgg-1 min-0.5) with a non-zero intercept for both the powdered and granular activated forms of activated carbons, respectively. The critical regions are the transfer of $\mathrm{Hg}$ (II) ions and the diffusion of activated carbon particles.

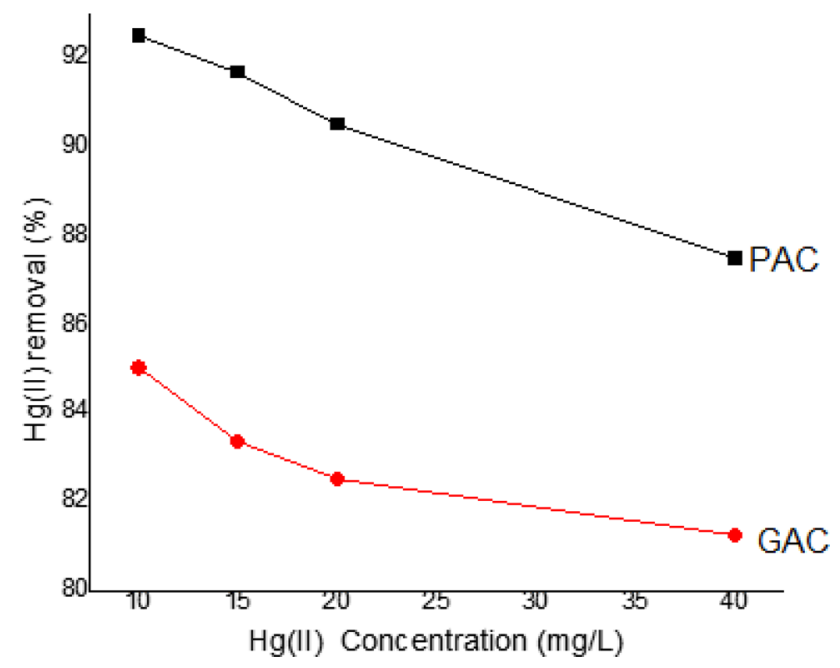

Fig. $7 \mathrm{Hg}$ (II) removal (\%) versus $\mathrm{Hg}$ concentration (mg/L) for powdered activated carbon (PAC) and granular activated carbon (GAC) at $30 \mathrm{~min}$. contact time, $20 \mathrm{~g}$ adsorbent, $\mathrm{pH}=6.05$

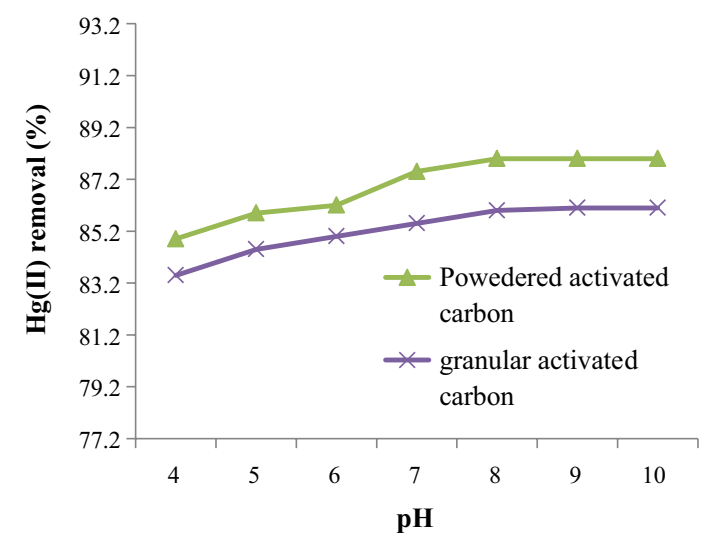

Fig. $8 \mathrm{Hg}$ (II) removal (\%) versus $\mathrm{pH}$ for powdered activated carbon (PAC) and granular activated carbon (GAC) at contact time $30 \mathrm{~min}$, $20 \mathrm{~g}$ adsorbent, $40.41 \mathrm{mg} / \mathrm{L} \mathrm{Hg}$ (II) ions

The boundary layers controlled the diffusion process thus making the plot to possess a non-zero intercept.

\section{Adsorption and reaction kinetics}

The contact time of the reaction is the critical component of the reaction kinetics. (Fig. 5). The criteria for evaluation include a contact time range of $30-210 \mathrm{~min}$ at a constant 


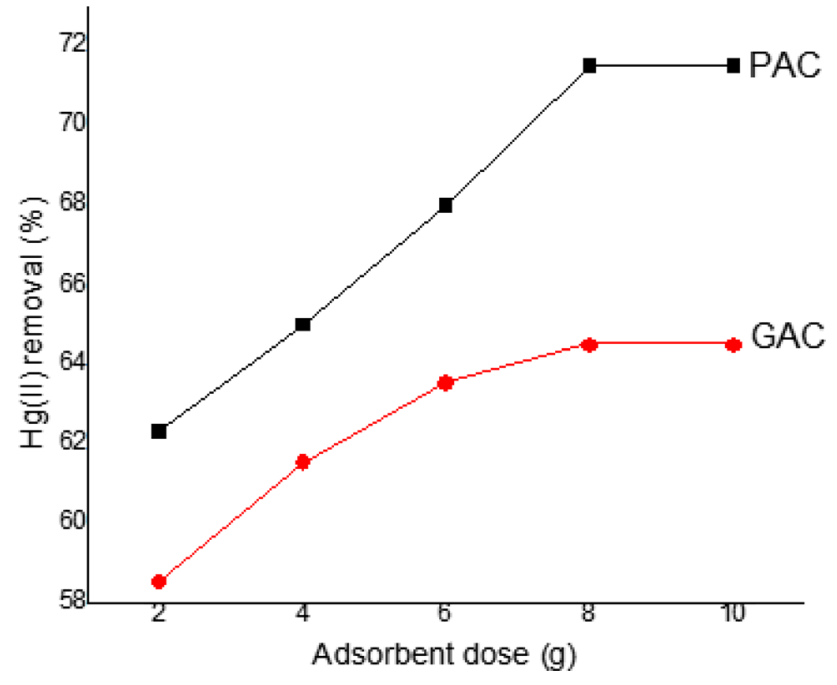

Fig. $9 \mathrm{Hg}(\mathrm{II})$ removal (\%) versus dose of powdered activated carbon (PAC) and granular activated carbon (GAC) at contact time $30 \mathrm{~min}, \mathrm{pH}=6.05,40.41 \mathrm{mg} / \mathrm{L} \mathrm{Hg}(\mathrm{II})$ ions

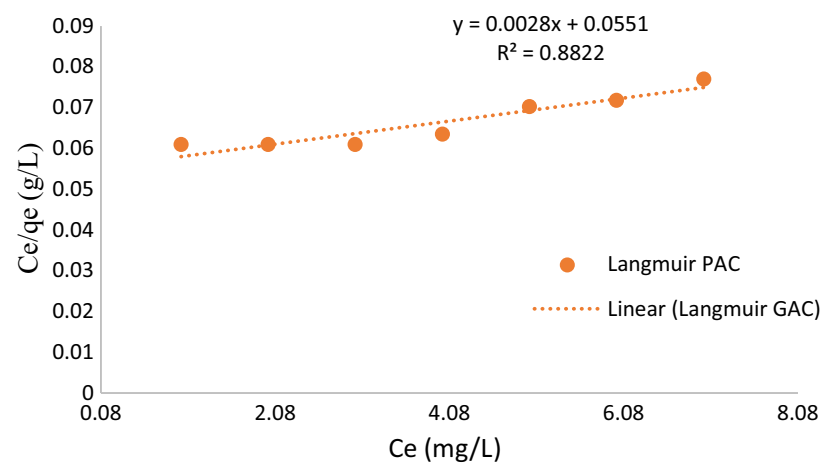

Fig. 10 Plot of $\mathrm{C}_{\mathrm{e}} / \mathrm{q}_{\mathrm{e}}$ versus $\mathrm{C}_{\mathrm{e}}$ for Langmuir isotherm for PAC

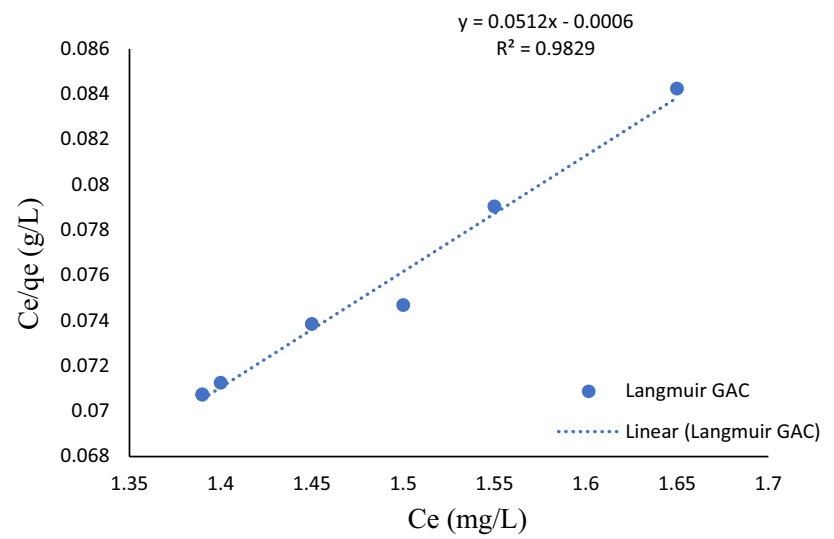

Fig. 11 Plot of $\mathrm{C}_{\mathrm{e}} / \mathrm{q}_{\mathrm{e}}$ versus $\mathrm{C}_{\mathrm{e}}$ for Langmuir isotherm for GAC
Table 5 linear fit analysis derived from Fig. 3 for PAC and GAC

\begin{tabular}{llll}
\hline Equation & $y=a+b^{*} \mathrm{x}$ & \multicolumn{2}{l}{ Powdered Activated Carbon } \\
\cline { 3 - 4 } & & Value & Standard error \\
\hline Adsorption & Intercept & 9.85 & $1.01 \times 10^{-6}$ \\
capacity (mg/g) & Slope & $3.22 \times 10^{-3}$ & $4.02 \times 10^{-8}$ \\
Equation & $y=a+b^{*} \mathrm{x}$ & Granular Activated Carbon \\
& & Value & Standard error \\
Adsorption capacity & Intercept & 9.85 & $1.01 \times 10^{-6}$ \\
(mg/g) & Slope & $3.22 \times 10^{-3}$ & $4.02 \times 10^{-8}$ \\
\hline
\end{tabular}

Table 6 Langmuir parameters for mercury adsorbed by powdered activated carbon

\begin{tabular}{llllll}
\hline $\mathrm{pH}$ & $x$ & $Y\left(*^{-2}\right)$ & $R^{2}$ & $b(\mathrm{~L} / \mathrm{mg})$ & $\mathrm{q}_{\mathrm{m}}(\mathrm{mg} / \mathrm{g})$ \\
\hline 4 & 1.20 & 6.091 & 0.88 & 317.43 & 19.70 \\
5 & 1.20 & 6.09 & 0.88 & 317.43 & 19.70 \\
6 & 1.2 & 6.09 & 0.88 & 317.43 & 19.70 \\
7 & 1.25 & 6.34 & 0.88 & 304.54 & 19.68 \\
8 & 1.38 & 7.02 & 0.88 & 275.40 & 19.65 \\
9 & 1.41 & 7.17 & 0.88 & 269.44 & 19.64 \\
10 & 1.51 & 7.69 & 0.88 & 251.27 & 19.62 \\
\hline
\end{tabular}

Table 7 Langmuir parameters for mercury adsorbed by granular activated carbon

\begin{tabular}{llllll}
\hline $\mathrm{pH}$ & $X$ & $Y\left(^{*-2}\right)$ & $R^{2}$ & $b(\mathrm{~L} / \mathrm{mg})$ & $\mathrm{q}_{\mathrm{m}}(\mathrm{mg} / \mathrm{g})$ \\
\hline 4 & 1.39 & 7.07 & .98 & 272.15571 & 19.65 \\
5 & 1.39 & 7.07 & .98 & 272.15 & 19.65 \\
6 & 1.40 & 7.12 & .98 & 270.17 & 19.65 \\
7 & 1.45 & 7.38 & .98 & 260.69 & 19.63 \\
8 & 1.50 & 7.64 & .98 & 251.84 & 19.62 \\
9 & 1.55 & 7.90 & .98 & 243.56 & 19.61 \\
10 & 1.65 & 8.42 & 98 & 228.51 & 19.58 \\
\hline
\end{tabular}

temperature, mercury concentration of $20 \mathrm{mg} / \mathrm{L}$ and $\mathrm{pH}=4-10$. Again, two critical components of the reaction are presented. These are a steady increase in adsorption until an equilibrium state is achieved. Before the steadystate, $\mathrm{Hg}$ (II) ions are deposited at available reactive sites (Rafatullah et al. 2011). and consequently, filled since and become saturated (Anirudhan and Sreekumari 2011; Vazquez et al. 2002). Besides, the higher exposed surface area for the powdered activated carbon and the lower surface area for the granular form of activated carbon differentiated the adsorption efficiencies. Both of the Freundlich and Langmuir isotherms indicate greater values for PAC compared to the GAC. 


\section{Effect of $\mathrm{Hg}$ (II) concentration on its removal by activated carbons}

In nature, aquatic systems possess a variable range of $\mathrm{Hg}$ concentrations. A mercury increase in solution decreased the adsorption of $\mathrm{Hg}(\mathrm{II})$ ions (Fig. 6) for both forms of activated carbons. The surface-reactive sites are occupied steadily until saturation is reached. Thus, there are retention of $\mathrm{Hg}$ (II) ions on activated carbon at a low concentration, and there is ready removal of $\mathrm{Hg}$ (II) ions at this stage of the reaction process.

\section{Effect of pH on mercury removal}

$\mathrm{pH}$ promotes the attachment of $\mathrm{Hg}(\mathrm{II})$ ions to the reactive functional groups of active carbon (Fig. 7). $\mathrm{pH}$ increase increased the deprotonation of these active carbon sites, thus, enhancing a negative charge (Burakov et al. 2018). There is a generation of bonding based on electrostatic attraction. Around the $\mathrm{pHzpc}$, there is reduced protonation and improved hydroxylation, which enhances $\mathrm{Hg}$ (II) removal from solution. Thus, intraparticle diffusion sets in and reorganized the reactive sites of the active carbon surfaces (Banerjee \& Chattopadhyaya 2017). The decrease in $\mathrm{pH}$ decreased $\mathrm{Hg}$ (II) removal. There is a competition for reactive sites between hydronium and $\mathrm{Hg}$ (II) ions, thus, impeding the removal of mercury ions in the solutions (Zheng et al. 2017).

\section{Effect of dosage of active carbon on the removal of $\mathrm{Hg}(\mathrm{II})$ ions}

The interaction of doses of active carbon and $\mathrm{Hg}$ (II) ions is represented (Fig. 8). The increase in the dosage of active carbon increased $\mathrm{Hg}$ (II) removal. When active carbon is increased, there is a consequent increase in active sites supported by increased surface area due to a increase in available reactive sites and surface area of active carbon. At the onset of coagulation of active particles, a steady-state of reaction is achieved (Fig. 8).

\section{Comparison of performance of adsorption parameters}

In comparing, the parameters of the adsorption of $\mathrm{Hg}$ (II) ions $\mathrm{pH}$ recorded the highest adsorption efficiency of $88 \%$ PAC and $86.1 \%$ for GAC at $\mathrm{pH}$ a range of $\mathrm{pH}-8-10$ and $\mathrm{pH}=9-10$, respectively. This parameter is followed by the concentration of mercury in solution. This parameter recorded $87.5 \%$ and $81.25 \%$ for $\mathrm{GAC}$ at $10 \mathrm{mg} / \mathrm{L}$ of $\mathrm{Hg}$ (II) concentration. The contact time was found to record $78 \%$ and $74.5 \%$ (i.e., for PAC and GAC), respectively, at the range of 150-210 min. The dosage of active carbon recorded the lowest adsorption efficiencies of $71.5 \%$ and $63.5 \%$ using powdered and granular forms of activated carbon.-

\section{Conclusions}

Both forms of active carbons are novel in removing $\mathrm{Hg}(\mathrm{II})$ ions from aqueous systems Protonation and deprotonation controlled by $\mathrm{pH}$ regulates the adsorption process. A twointeraction process namely mass transfer of active particles and intraparticle diffusion controlled by a boundary layer are involved in the removal mechanism for $\mathrm{Hg}$ (II) ions. There is evidence that two-reaction steps namely a step whereby the reaction is gradual and a steady-state at equilibrium. There is evidence that the active sites at carbon surfaces get filled over time, thus, promoting the two-step reaction. The presence of hydronium ions promotes the hydroxylation of the system, thus, creating a reorganization of the active. Both of the Freundlich and Langmuir isotherms fit into the experimental data.

Acknowledgments The authors are grateful to the authority of the Niger Delta University for the release of research allowances used for this project.

Author contributions All authors confirm that there are no financial and personal relationships with other people or organizations that could inappropriately influence this study.

Funding The authors acknowledged the release of research allowances by authorities of the Corresponding Author's institution SL20182019.

\section{Compliance with ethical standards}

Conflict of interest No potential conflict of interest was reported by the authors.

Open Access This article is licensed under a Creative Commons Attribution 4.0 International License, which permits use, sharing, adaptation, distribution and reproduction in any medium or format, as long as you give appropriate credit to the original author(s) and the source, provide a link to the Creative Commons licence, and indicate if changes were made. The images or other third party material in this article are included in the article's Creative Commons licence, unless indicated otherwise in a credit line to the material. If material is not included in the article's Creative Commons licence and your intended use is not permitted by statutory regulation or exceeds the permitted use, you will need to obtain permission directly from the copyright holder. To view a copy of this licence, visit http://creativecommons.org/licenses/by/4.0/.

\section{References}

Abdel-Ghani NT, El-Chaghaby GA (2014) Biosorption for metal ions removal from aqueous solutions: a review of recent studies. Int J Latest Res SciTechnol 3(1):24-42 
Abdolali A, Guo WS, Ngo HH, Chen SS, Nguyen NC, Tung KL (2014) Typical lignocellulosic wastes and by-products for biosorption process in water and wastewater treatment: a critical review. BioresourTechnol 160:57-66. https://doi.org/10.1016/j.biort ech.2013.12.037

Alam MF, Akhter M, Mazumder B, Ferdous A, Hossain MD, Dafader NC, Ahmed FT, Kundu SK, Taheri T, Ullah AA (2019) 'Assessment of some heavy metals in selected cosmetics commonly used in Bangladesh and human health ris'k. J Anal SciTechnol 10(1):2. https://doi.org/10.1186/s40543-018-0162-0

Ani JU, Akpomie KG, Okoro UC, Aneke LE, Onukwuli OD, Ujam OT (2020) Potentials of activated carbon produced from biomass materials for sequestration of dyes, heavy metals, and crude oil components from aqueous environment. Appl Water Sci 10(2):69. https://doi.org/10.1007/s13201-020-1149-8

Anirudhan TS, Sreekumari SS (2011) Adsorptive removal of heavy metal ions from industrial effluents using activated carbon derived from waste coconut buttons. J Environ Sci 23(12):1989-1998. https://doi.org/10.1016/S1001-0742(10)60515-3

Avigliano E, Monferrán MV, Sánchez S, Wunderlin DA, Gastaminza J, Volpedo AV (2019) Distribution and bioaccumulation of 12 trace elements in water, sediment and tissues of the main fishery from different environments of the La Plata basin (South America): risk assessment for human consumption. Chemosphere 236:124394. https://doi.org/10.1016/j.chemosphere.2019.124394

Awual MR (2017) Novel nanocomposite materials for efficient and selective mercury ions capturing from wastewater. ChemEng $\mathbf{J}$ 307:456-465. https://doi.org/10.1016/j.cej.2016.08.108

Banerjee S, Chattopadhyaya M (2017) Adsorption characteristics for the removal of a toxic dye, tartrazine from aqueous solutions by a low-cost agricultural by-product. Arabian J Chem 10:1629-1638. https://doi.org/10.1016/j.arabjc.2013.06.005

Bani O, Aryani N, Kaban GS (2018) Preparation of activated carbonbased catalyst from candlenut shell impregnated with $\mathrm{KOH}$ for biodiesel production. Key Eng Mater (Trans Tech Publ), 262267. https://doi.org/https://doi.org/10.4028/www.scientific.net/ KEM.777.262

Budianto A, Kusdarini E, Effendi S, Aziz M., (2019) the production of activated carbon from indonesian mangrove charcoal. IOP Conference Series: Materials Science and Engineering, 2019 IOP Publishing, 012006. https://doi.org/https://doi.org/10.1088/1757899X/462/1/012006

Burakov AE, Galunin EV, Burakova IV, Kucherova AE, Agarwal S, Tkachev AG, Gupta VK (2018) Adsorption of heavy metals on conventional and nanostructured materials for wastewater treatment purposes: a review. Ecotoxicol Environ Saf 148:702-712. https://doi.org/10.1016/j.ecoenv.2017.11.034

Chen C, Duan Y, Zhao S, Hu B, Li N, Yao T, Zhao Y, Wei H, Ren S (2019) Experimental study on mercury removal and regeneration of SO2 modified activated carbon. IndEngChem Res 58(29):13190-13197. https://doi.org/10.1021/acs.iecr.8b06063

Di Stasi C, Alvira D, Greco G, González B, Manyà JJ (2019) Physically activated wheat straw-derived biochar for biomass pyrolysis vapors upgrading with high resistance against coke deactivation. Fuel 255:115807. https://doi.org/10.1016/j.fuel.2019.115807

Dong H (2012) Clay-microbe interactions and implications for environmental mitigation. Elements 8:113-118. https://doi.org/10.2113/ gselements.8.2.113

Fuadi NA, Ibrahem AS, Ismail KN (2014) Removal of heavy metals from simulated wastewater using physically and chemically modified palm shell activated carbon. J ApplSci 14:1294. https://doi. org/10.3923/jas.2014.1294.1298

Ghaith E.-SI, Rizvi S, Namasivayam C, Rahman P., (2019). Removal of $\mathrm{Cd}++$ from contaminated water using bio-surfactant modified ground grass as a bio-sorbent. Advances in Science and
Engineering Technology International Conferences (ASET), IEEE, 1-7. https://doi.org/https://doi.org/10.1109/ICASE T.2019.8714467

Hui TS, Zaini MAA (2015) Potassium hydroxide activation of activated carbon: a commentary. Carbon Lett 16:275-280. https:// doi.org/10.5714/CL.2015.16.4.275

Jankovi B, Mani N, Dodevski V, Radovi I, Pijovi M, Katn I, Tasi G (2019) Physico-chemical characterization of carbonized apricot kernel shell as precursor for activated carbon preparation in clean technology utilization. J Cleaner Production 236:117614. https:// doi.org/10.1016/j.jclepro.2019.117614

Joseph L, Jun BM, Flora JR, Park CM, Yoon Y (2019) 'Removal of heavy metals from water sources in the developing world using low-cost materials: a review. Chemosphere 229:142-159. https:// doi.org/10.1016/j.chemosphere.2019.04.198

Lotfy HR, Misihairabgwi J, Mutwa MM (2012) The preparation of activated carbon from agroforestry waste for wastewater treatment. Afr J Pure ApplChem 6:149-156

Mohan D, Chander S (2001) Single component and multi-component adsorption of metal ions by activated carbons. Colloids Surf A 177:183-196. https://doi.org/10.1016/S0927-7757(00)00670-1

Mousavi A, Chávez RD, Ali AM, Cabaniss SE (2011) Mercury in natural waters: a mini-review. Environ Forensics 12(1):14-18. https:// doi.org/10.1080/15275922.2010.547549

Ojemaye MO, Okoh OO, Okoh AI (2017) Surface modified magnetic nanoparticles as efficient adsorbents for heavy metal removal from wastewater: progress and prospects. Mater Express 7:439-456. https://doi.org/10.1166/mex.2017.1401

Páez-Hernández ME, Aguilar-Arteaga K, Galán-Vidal CA, PalomarPardavé M, Romero-Romo M, Ramírez-Silva MT (2005) Mercury ions removal from aqueous solution using an activated composite membrane. Environ SciTechnol 39(19):7667-7670. https://doi. org/10.1021/es0505705

Rafatullah M, Sulaiman O, Hashim R, Amini M (2011) Adsorption of copper (II) ions onto surfactant-modified oil palm leaf powder. J DispersSciTechnol 32:1641-1648. https://doi.org/10.1080/01932 691.2010 .528340

Sadegh H, Mazloumbilandi M, Chahardouri M (2017) Low-cost materials with adsorption performance. Handbook Ecomater. https:// doi.org/10.1007/978-3-319-48281-1_175-1

Šapanin A, Smajovi A, Peh E, Salihovi M, Jan?An G., (2019). 'Health risk assessments based on the contents of heavy metals in sarajevo urban soil. International Conference New Technologies, Development and Applications, 2019. Springer, 595-603. https://doi. org/https://doi.org/10.1007/978-3-030-18072-0_69

Shahadat M, Isamil S (2018) Regeneration performance of clay-based adsorbents for the removal of industrial dyes: a review. RSC Adv 8(43):24571-24587. https://doi.org/10.1039/c8ra04290j

Skinner K, Wright N, Porter-Goff E (2007) Mercury uptake and accumulation by four species of aquatic plants. Environ Poll 145(1):234-237. https://doi.org/10.1016/j.envpol.2006.03.017

Stoeckli F, Centeno TA (2005) On the determination of surface areas in activated carbons. Carbon 43:1184-1190. https://doi. org/10.1016/j.carbon.2004.12.010

Thambiliyagodage C, Cooray V, Perera I, Wijesekera R., (2018). 'Eco-Friendly Porous Carbon'. Materials for Wastewater Treatment. International Conference on Sustainable Built Environment, 2018. Springer, 252-260. https://doi.org/https://doi. org/10.1007/978-981-13-9749-3_23

Vazquez G, Gonzalez-Alvarez J, Freire S, López-Lorenzo M, Antorrena G (2002) Removal of cadmium and mercury ions from aqueous solution by sorption on treated Pinuspinaster bark: kinetics and isotherms. BioresTechnol 82(3):247-251. https://doi.org/10.1016/ S0960-8524(01)00186-9

Wan WMH, Mohamad AMH, Sulaiman NS, Yacob AR, Hanapi SZ, Inderan V, Yacob AR, Hanapi SZ, Inderan V, Dasril RS., (2010). 
'Nano-tungsten carbide prepared from palm kernel shell for catalytic decomposition of hydrazine'. In Chemical, Biological And Environmental Engineering, 334-338.

Yang X, Wan Y, Zheng Y, He F, Yu Z, Huang J, Wang H, Ok YS, Jiang Y, Gao B (2019) Surface functional groups of carbon-based adsorbents and their roles in the removal of heavy metals from aqueous solutions: a critical review. ChemEng J 366:608-621. https://doi. org/10.1016/j.cej.2019.02.119

Zbair M, Ahsaine HA, Anfar Z, Slassi A (2019) Carbon microspheres derived from walnut shell: Rapid and remarkable uptake of heavy metal ions, molecular computational study and surface modeling. Chemosphere 231:140-150. https://doi.org/10.1016/j.chemospher e.2019.05.120
Zheng M, Hu Q, Zhang S, Tang H, Lil PH (2017) Macroporous activated carbon derived from rapeseed shell for lithium-sulfur batteries. ApplSci 7:1036. https://doi.org/10.3390/app7101036

Zheng C, Ma X, Yao Z, Chen X (2019) The properties and combustion behaviors of hydrochars derived from co-hydrothermal carbonization of sewage sludge and food waste. BioresTechnol 285:121347. https://doi.org/10.1016/j.biortech.2019.121347

Publisher's Note Springer Nature remains neutral with regard to jurisdictional claims in published maps and institutional affiliations. 